\title{
MÉNAGE, Gilles. Historia de las Mujeres Filósofas, Barcelona, Herder editorial, 2009, 160p. ISBN: 8425425816 ISBN-13: 9788425425813
}

O livro é pequeno. A edição, primorosa: capa dura com sobrecapa ilustrada pela reprodução de uma estátua, ao que parece, de uma filósofa antiga, grega talvez. Data de 1690 a primeira edição, ampliada e ligeiramente corrigida em uma 2a edição, em 1692. Seu autor, Gilles Ménage, nasceu em 1613, em Angers, e morreu em Paris em 1692, onde viveu grande parte de sua vida. Lexicógrafo, gramático, latinista, figura controvertida que inspirou Molière na criação do personagem Vadius, de sua peça Les Femmes Savantes. De que trata a obra? Ménage nos oferece uma espécie de enciclopédia com mais de 60 nomes de filósofas que viveram entre os séculos XII a.C. e XIV d.C.

O curioso e atraente nessa obra é que revela algo que livros de História da Filosofia ignoram: Houve, sim, mulheres filósofas na Antiguidade, ainda que seus nomes não constem em currículos escolares ou em livros de referência da área. Linda López McAlister, em artigo publicado na revista Hypatia, (vol.4, $\mathrm{n}^{\circ} 1$, Spring, 1989, p. 1-5), Some Remarks on Exploring the History of Women in Philosophy, conta sua experiência como estudante de Filosofia nos anos 50. ${ }^{1} \mathrm{No}$ decorrer da graduação, assim como da pós, nunca ouviu um nome de filósofa ser mencionado, à exceção de algumas poucas contemporâneas. Em 1967, quando foram publicados os oito volumes da Encyclopedia of Philosophy, dirigida por Paul Edwards, com perto de 1,5 mil verbetes e a contribuição de cerca de 500 autores, Linda buscou avidamente saber o que havia sobre mulheres filósofas nessa obra que se pretendia compreensiva. Nada! Apenas uma rápida menção a Hildegarde de Bingen, apesar de, segundo suas palavras, haver inúmeros pequenos artigos sobre obscuras figuras masculinas. ${ }^{2}$ Sua conclusão à época: não há nada e não se menciona porque não houve mulheres dedicadas à Filosofia antes.

O próprio Ménage fala, no prefácio de seu livro, de sua surpresa pela ausência de referências a mulheres filósofas em obras de escritores de renome (p.45).

$\mathrm{Na}$ introdução à sua tradução da obra para o inglês, Beatrice Zedler nota que o autor deseja mostrar que, de fato, não houve falta de mulheres fllósofas, mas uma falta em nosso conhecimento sobre elas. ${ }^{3}$ Umberto Ecco vai na mesma direção, ao comentar a tradução da obra para o francês: "No es que no hayan existido mujeres que filosofaran. Es que los filósofos han preferido olvidarlas, tal vez después de haberse

\footnotetext{
${ }^{1}$ http://www.jstor.org/pss/3809930, acesso em $1^{\circ}$ dezembro, 2010.

${ }^{2}$ A tradução dos textos em língua estrangeira é da autora da resenha.

${ }^{3}$ Cit. In GEORGE, Lynda, Gender Equity: In Search of Diotima's Place With the Ancient Philosophers, Forum on Public Policy, 2006, p. 5. http://www.forumonpublicpolicy.com/archivesum07/george.pdf, acesso em 1ª, dezembro, 2010.
} 
apropiado de sus ideas". ${ }^{4}$ Como o demonstra Lynda George, não apenas esquecidas, as mulheres filósofas tiveram, mesmo, negada sua existência. Foi o que aconteceu com Diotima. A partir do século XV, Diotima passou a ser considerada personagem de ficção, apesar de haver suficientes evidências históricas de que foi uma mulher, filósofa, real, que influenciou Platão. ${ }^{5}$ Em outras áreas, outras mulheres sofreram processo semelhante: a Papisa Joana, sobre cuja existência real até hoje pairam dúvidas, e Trotula de Ruggiero, médica e cientista de prestígio cujo nome foi mudado para o masculino, Trotus, passando à história como homem. ${ }^{6}$

O "esquecimento" das mulheres, sua ausência nos relatos históricos, é persistente. Michelle PERROT, em obra recente, o indica desde o título: As Mulheres ou os silêncios da História. ${ }^{7}$ Lemos logo na Introdução:

No início era o Verbo, mas o Verbo era Deus, e Homem. O silêncio é o comum das mulheres. Ele convém à sua posição secundária e subordinada. [...] $\mathrm{O}$ silêncio é um mandamento reiterado através dos séculos pelas religiōes, pelos sistemas políticos e pelos manuais de comportamento". ${ }^{8}$

E, no Brasil, escrevem os organizadoros do Dicionário Mulheres do BrasilDe 1500 até a atualidade: "Constatamos, enfim, que a história das mulheres é uma história recente e que se ressente de um passado mal contado". ${ }^{9}$

Essa histórica situação de esquecimento e silêncio é evocada para indicar a importância do trabalho de Ménage. Não se trata de uma História da Filosofia propriamente, pois o autor não apresenta o conteúdo do pensamento filosófico

\footnotetext{
${ }^{4}$ Cit. In GATELL, Rosa Rius, Introducción. MÉNAGE, Gilles. Historia de las Mujeres Filósofas, Barcelona, Herder editorial, 2009, p. 12.

${ }^{5}$ GEORGE, Lynda, Gender Equity: In Search of Diotima's Place With the Ancient Philosophers, Forum on Public Policy, 2006. http://www.forumonpublicpolicy.com/archivesum07/george.pdf, acesso em 1, dezembro, 2010. ${ }^{6}$ Sobre a Papisa Joana, entre muitos outros, pode-se ler: BOUREAU, Alain, La Papesse Jeanne. Paris:Aubier, 1988 e PARDOE, Rosemary e Darroll. A Papisa Joana: o mistério da mulher Papa - A primeira documentação completa sobre os fatos por trás da lenda. São Paulo: IBRASA, 1990. Sobre Trotula, cf VALERIO, Adriana. La questione femminile nei secoli X-XII. Napoli, M. D'auria Editore, 1983, p 43-44: [...]É il caso di Trotula de Ruggiero, allieva di Garioponto, "prestigiosa medichessa salernitana" della meta dell'XI secolo, autrice di uno dei testi più significativi prodotti daí Salernitani, "De mulierum passionibus", trascritto, elaborato e tradotto per quatro secoli. Questo trattato, che segna per alcuni studiosi la nascita dell'ostetricia e della ginecologia come scienza medica, è estremamente interessante per la visione globale del corpo umano che esso offre. [...] Dal XVI secolo in poi, però, il nome di Trotula sarà modificato e transformato, com uma serie di variantim da femminile in maschile, Trotus, e delle donne salernitane si perderanno le tracce. È sintomatico che lo storico A. De Stefano, nello studio sulla cultura ala corte di Federuco II, parli della scuola salernitana di medicina, ma non faccia alcun cenno alle donne che pure vi hanno svolto un ruolo cosi prestigioso. (Sublinhado pela autora da resenha.

${ }^{7}$ PERROT, Michelle, As Mulheres ou os silêncios da História. Bauru, SP, EDUSC, 2005.

${ }^{8}$ Id. p.9.

9 SCHUMAHER, Schuma e BRAZIL, Érico Vital, do Dicionário Mulheres do Brasil - De 1500 até a atualidade, Rio de Janeiro, Jorge Zahar Editor, 2000, p.10.
} 
de cada uma das mulheres mencionadas. Ménage indica apenas quem são elas, as fontes em que aparecem mencionadas e as escolas filosóficas às quais se filiam. Mesmo assim, Mary Ellen Waithe, editora de uma História de Mulheres Filósofas, em 1987, refere o livro de Ménage como a principal fonte inspiradora de seu trabalho. ${ }^{10}$ Também Zedler fala dessa obra como ponto de partida para a reconstrução histórica do pensamento filosófico das mulheres. ${ }^{11}$

Como se lê na contracapa da edição espanhola, o autor "devuelve la palabra a pensadoras silenciadas por la historia, las rescata del mero papel de hijas, esposas o amantes de notables ilósofos y las considera protagonistas de um quehacer intelectual em pie de igualdad com el resto de los pensadores". Por que o fez? Como explicar seu interesse em tornar público o trabalho dessas pensadoras da Antiguidade? Das referências à sua biografia, pode-se afirmar que ele viveu muito próximo a um círculo de mulheres savantes, frequentadoras e criadoras de salōes de conversação, comuns à época. Foi preceptor de algumas dessas mulheres. Dessa sua presença nos salóes femininos, informa Rosa Rius Gatell em sua introdução à presente tradução para o espanhol, recolheu "testimonios directos de um espacio de transformación creado, mantenido y desarrollado por mujeres". Nesses salōes, a conversa se tornou um espaço de formação do pensamento, um princípio civilizador. Ménage dialogou com essas mulheres, reconheceu sua inteligência admirou seus conhecimentos e também seus escritos. Gatell conclui que ele escreveu sua Historia de las Mujeres Filósofas em honra de suas amigas. Porém, não apenas por isso. $\mathrm{O}$ livro teria sido escrito em latim para, quem sabe, chamar a atenção de outros intelectuais da época para as pensadoras do passado e para refutar a opinião corrente de que não teria havido filósofas na Antiguidade. Mas também para que suas contemporâneas soubessem que não eram as primeiras a construir Filosofia.

Sobre o conteúdo da obra, lemos na introdução que Ménage segue o método e o estilo de Laércio em sua Vida [y opiniones] de los filósofos ilustres. Como o autor grego, recorre a inúmeras fontes e dedica seu livro a uma mulher: Anne Lefebvre Dacier. As filósofas listadas são agrupadas em onze categorias, segundo diversas escolas filosóficas: Platônica, Acadêmica, Dialética, Cirenaica, Magárica, Cínica, Peripatética, Epicurista, Estóica, Pitagórica e aquelas que o autor coloca como de "escola incerta". Os critérios do autor para incorporar uma mulher a sua lista são variados: desde o fato de haver sido reconhecida por algum autor antigo como culta, ou mesmo como filósofa, até haver participado de atividades relacionadas à Filosofia ou ter vínculos familiares ou de discipulado com algum filósofo.

\footnotetext{
${ }^{10}$ Gatell, Rosa Rius, Introducción. MÉNAGE, Gilles. Historia de las Mujeres Filósofas, Barcelona, Herder editorial, 2009, p.34.

${ }^{11}$ Id.ibidem
} 
196 Maria José Rosado

Ao final da leitura, diz Gatell, gostaríamos, na verdade, de saber muito mais sobre o pensamento dessas filósofas do que nos oferece Ménage. Podemos reconhecer, no entanto, que, ainda assim, o trabalho dele é inspirador de pesquisas a respeito das contribuições de mulheres para a construção do pensamento filosófico.

Maria José Rosado (mjrosado@uol.com.br) 